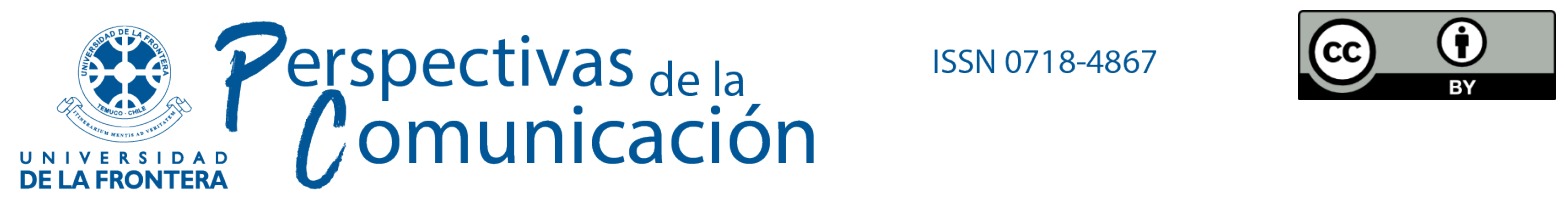

Documento

\title{
CINE ARGENTINO EN BRASIL: INTEGRACIÓN, COOPERACIÓN Y COMPETENCIA ${ }^{1}$
}

https://doi.org/OO.OOO/COO-2O2O-O1

\author{
Mg. Leandro González \\ Universidad Nacional de General Sarmiento, Buenos Aires, Argentina \\ legonzal@ungs.edu.ar \\ ORCID: https://orcid.org/oooo-0001-9773-0517
}

\section{Resumen}

$\mathrm{El}$ artículo pretende hacer un aporte al creciente conjunto de investigaciones que abordan las relaciones cinematográficas entre Argentina y Brasil, analizando específicamente la circulación del cine argentino en Brasil y enfatizando la importancia de las políticas culturales (nacionales y supranacionales) que moldean los intercambios.

El análisis se nutre de la compilación y el procesamiento de estadísticas culturales producidas por fuentes oficiales, a partir de las cuales se realiza una caracterización del mercado brasileño y se ofrece un panorama sobre los procesos de integración regional que involucran a ambos países (Ibermedia y RECAM). Luego se analiza en profundidad la presencia y performance del cine argentino en Brasil, analizando por separado las coproducciones argentino-brasileñas y el resto de las películas de nacionalidad argentina, ya que -como se argumentará- se trata de objetos jurídicamente distintos.

\footnotetext{
1 En 2019 este artículo obtuvo el Premio "Octavio Getino" de estudios en política audiovisual (artículo publicado en el período 2018-2019, en revistas de la especialidad de comunicación), otorgado por la ULEPICC (Unión Latina de Economía Política de la Información, la Comunicación y la Cultura). Originalmente fue publicado en la revista Archivos de la Filmoteca, a la cual le agradecemos la autorización para esta nueva publicación. La referencia original es la siguiente: González, L. (2019). "Cine argentino en Brasil: integración, cooperación y competencia”. Archivos de la Filmoteca 76, 53-72 ISSN 0214-6606 SSN electrónico 2340-2156. http://www.archivosdelafilmoteca.com/index.php/archivos/article/view/657
} 
El interés por analizar las relaciones entre ambos países radica en que se encuentran entre los 15 mayores productores de largometrajes del mundo y son -junto a México- las industrias cinematográficas más poderosas de Latinoamérica. Cuentan con una trayectoria de décadas en materia de regulación y fomento al cine y con una serie de acuerdos de coproducción y cooperación que fortalecieron la integración. Desde la perspectiva argentina, Brasil se destaca por dos aspectos: representa el segundo destino internacional en importancia para el cine argentino y, en sí mismo, el mercado brasileño se ubica entre los diez más grandes del mundo en términos de espectadores. Finalmente, al analizar sistemáticamente estas relaciones se pretende contribuir a la comprensión del (nuevo) devenir global de la industria cinematográfica en el siglo XXI.

Palabras clave: cine argentino, cine transnacional, coproducción, Ibermedia, RECAM, INCAA, ANCINE. 


\title{
ARGENTINE CINEMA IN BRAZIL: INTEGRATION, COOPERATION AND COMPETITION
}

\begin{abstract}
The article aims to make a contribution to the growing body of research that addresses film relations between Argentina and Brazil, specifically analyzing the circulation of Argentine cinema in Brazil and emphasizing the importance of cultural policies (national and supranational) that shape exchanges.
\end{abstract}

The analysis is based on the compilation and processing of cultural statistics produced by official sources, from which a characterization of the Brazilian market is made and a panorama is offered on the processes of regional integration that involve both countries (Ibermedia and RECAM). Then, the presence and performance of Argentine cine-ma in Brazil is analyzed in depth, separately analyzing the Argentine-Brazilian co-productions and the rest of the movies of Argentine nationality, since -as will be argued- these are legally distinct objects.

The interest in analyzing relations between both countries is that they are among the 15 largest producers of feature films in the world and are -together with Mexico- the most powerful film industries in Latin America. They have a decades-long track record in terms of regulation and promotion of cinema and a series of co-production and cooperation agreements that strengthened the integration. From the Argentine perspective, Brazil stands out for two aspects: it represents the second most important international destination for Argentine cinema and, in itself, the Brazilian market is among the ten largest in the world in terms of viewers. Finally, systematically analyzing these relationships is intended to contribute to the understanding of the (new) global becoming of the film industry in the 21st century.

Keywords: Argentine cinema, transnational cinema, co-production, Ibermedia, RECAM, INCAA, ANCINE 


\section{INTRODUCCIÓN}

En los últimos años se registra un interés creciente por los intercambios de películas entre Argentina y Brasil, tanto en lo que respecta al periodo clásico-industrial (Gil, 2014; Autran, 2016) como al pasado reciente (Moguillansky, 2008, 2014; Daiello, 2011; Nazareno, 2017), por no hablar de una bibliografía más prolífica sobre los procesos de integración regional (Silva, 2007; Moguillansky, 2016; Carvalho, 2018) que involucran a las cinematografías de ambos países. Incluso existe un libro titulado Argentina-Brasil no cinema: diálogos (Amancio, 2014), donde se compilan trabajos de distintos autores que abordan la cuestión desde diversas perspectivas.

Este artículo pretende hacer un aporte a ese conjunto de indagaciones abordando específicamente la circulación del cine argentino en Brasil, enfatizando la importancia de las políticas culturales (nacionales y supranacionales) que moldean dichos intercambios y basándose fuertemente en el análisis de estadísticas culturales producidas por fuentes oficiales.

El texto se organiza en dos partes. En la primera, se caracteriza el mercado cinematográfico brasileño a partir de las principales variables, se ofrece un panorama sobre la participación de Argentina y Brasil en los procesos de integración regional y se analizan sus coproducciones internacionales. En la segunda parte se aborda la presencia y performance del cine argentino en Brasil analizando por separado las coproducciones argentinobrasileñas y el resto de las películas de nacionalidad argentina.

El interés por analizar las relaciones entre ambos países radica en que se encuentran entre los 15 mayores productores de largometrajes del mundo (UNESCO, 2017) y son -junto a México- las industrias cinematográficas más poderosas de Latinoamérica. Cuentan con una trayectoria de décadas en materia de regulación y fomento al cine y con una serie de acuerdos de coproducción y cooperación que multiplicaron los vínculos y fortalecieron la integración. Desde la perspectiva argentina, Brasil se destaca por dos aspectos: representa el segundo destino internacional en importancia para el cine argentino (sólo superado por España, ver Borello, González, Rud y Yoguel, 2018) y, en sí mismo, el mercado brasileño se ubica entre los diez más grandes del mundo en términos de espectadores (European Audiovisual Observatory, 2018). Finalmente, al analizar sistemáticamente estas relaciones se pretende contribuir a la comprensión del (nuevo) devenir global de la industria cinematográfica en el siglo XXI. 


\section{CARACTERIZACIÓN DEL MERCADO BRASILEÑO}

En el año 2016 funcionaron 3.160 salas en Brasil (Figura 1), la cifra más alta desde 1975 (cuando funcionaron 3.276) y una de las más altas de su historia (Freire y Hernandez, 2017). La exhibición comenzó a decaer a fines de los ‘70s y entró en crisis a mediados de los '9os, tal como lo documenta Anita Simis (2015), en un proceso similar al que se dio en la Argentina (González, 2015). No obstante, desde el cambio de siglo se observa un crecimiento prácticamente ininterrumpido, lo cual da cuenta tanto del dinamismo del mercado cinematográfico brasileño como así también de la vigencia de la exhibición theatrical, que se sostiene a pesar de la proliferación de las nuevas pantallas. Este dinamismo es impulsado principalmente por el modelo multiplex, es decir, por los más de 700 complejos cinematográficos que tienen varias salas en un mismo edificio.

Figura 1. Cantidad de salas y complejos, 1971-2016

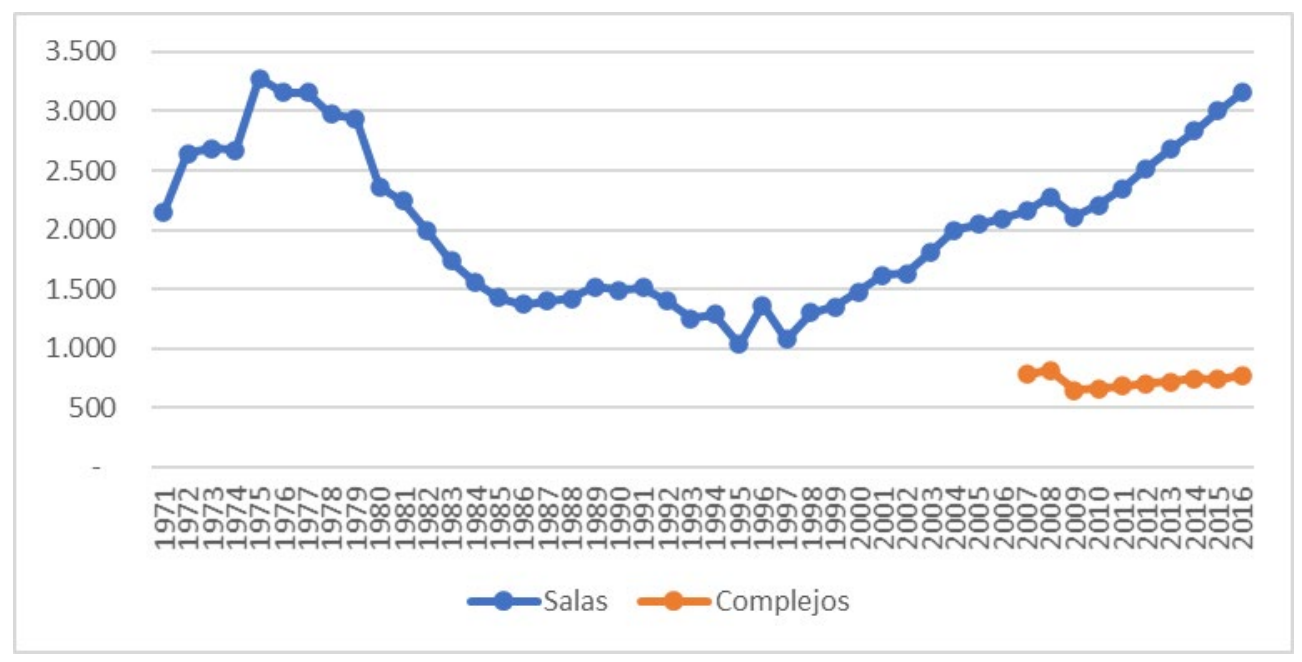

Fuente: OCA-ANCINE

En cuanto a la cantidad de películas que se exhiben, también se observa un claro crecimiento en el periodo corriente del siglo XXI (Figura 2). Ello se debe sobre todo al aumento de la producción brasileña, cuyo volumen se ha quintuplicado. En términos relativos (ver Figura 6), la participación de la producción local se duplicó, ya que pasó de representar el 15\% al $31 \%$ de los estrenos totales. 
Figura 2. Cantidad de estrenos, 2002-2016

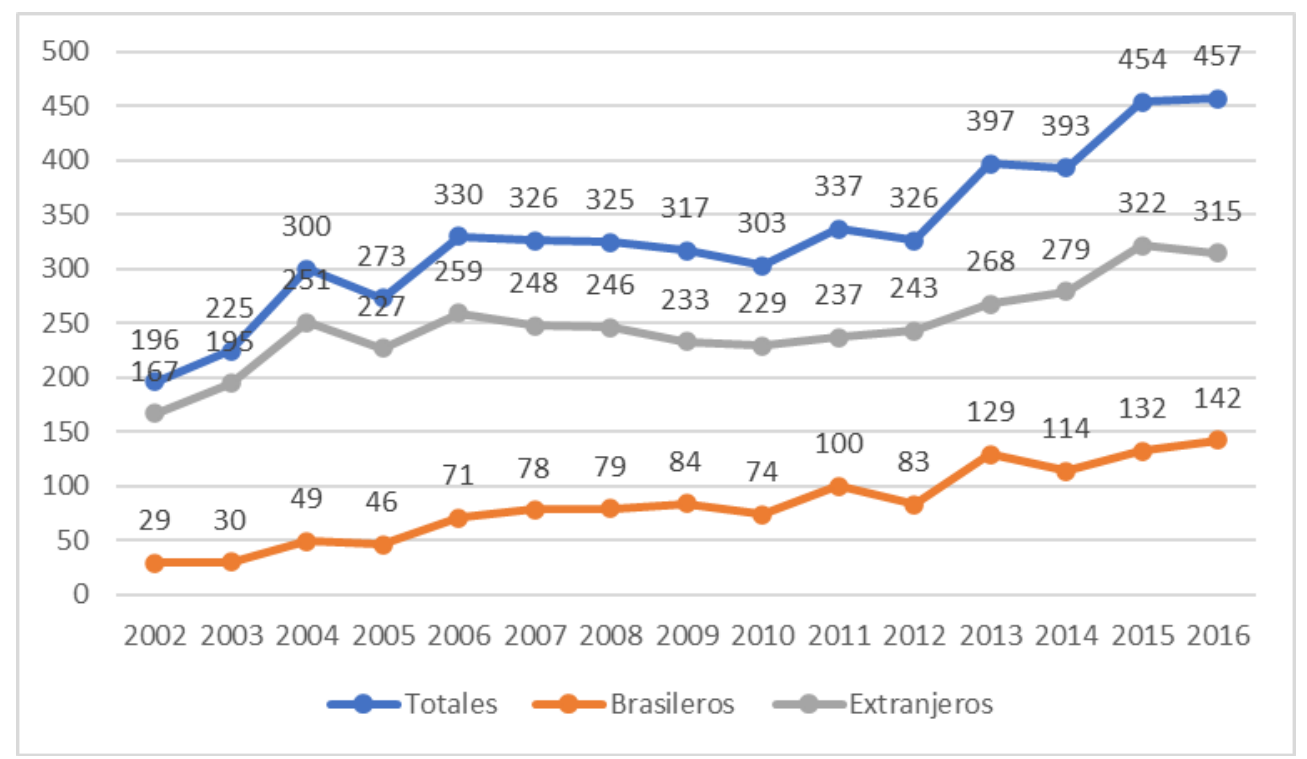

Fuente: OCA-ANCINE

No obstante, como en gran parte del planeta, la mayoría de los estrenos son de origen extranjero. Un análisis acotado al periodo 2009-2016 muestra que el 35\% de los lanzamientos fueron estadounidenses, seguidos por un 29\% locales y un $8 \%$ franceses (Figura 3). Un dato relevante señala una participación argentina muy modesta pero no insignificante (1,2\%), similar a la de España, Alemania e Italia. Más adelante se abordará en profundidad esta participación, que parece estar subestimada. 
Figura 3. Lanzamientos por país de origen, acumulado 2009-2016

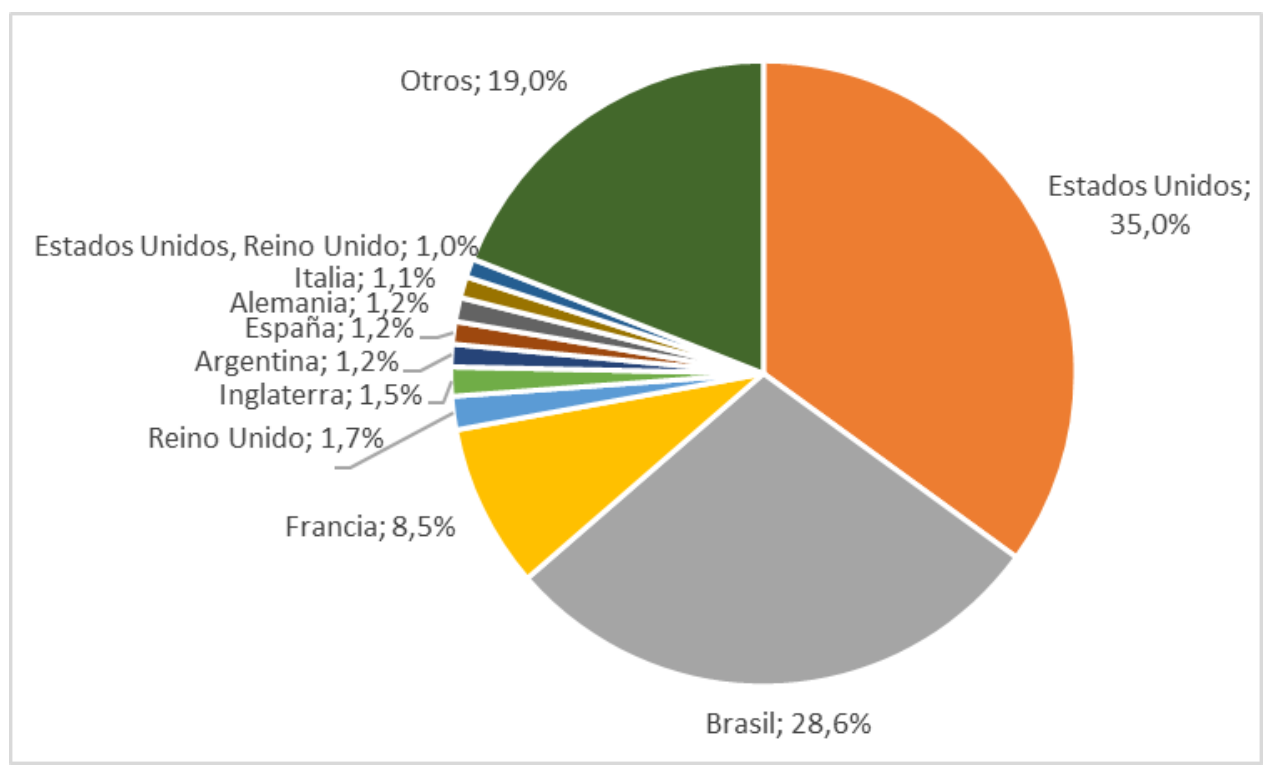

Fuente: OCA-ANCINE

El aumento en la exhibición y la producción ha sido acompañado por el consumo. El dato más contundente es que entre 2002 y 2016 se duplicó la cantidad de espectadores (Figura 4). En contraste con lo que pasa en la producción, en este caso la mayor parte del crecimiento se explica por el aumento del factor externo (es decir, espectadores que optan por el cine extranjero). Tal como puede observarse en la Figura 6, el market share local se mantiene relativamente estable en torno al $14 \%{ }^{2}$.

2 Los porcentajes son similares en Argentina. Francia y el Reino Unido tienen una cuota de mercado local del 37\%, mientras que España e Italia están levemente por debajo del 20\%. Luego, Turquía y Corea del Sur tienen más de la mitad de su mercado local (55\%, aproximadamente). Estados Unidos, por su parte, tiene una cuota cercana al $90 \%$.

Fuentes: Borello, González, Rud y Yoguel (2018) y "EU gross box office topped EUR 7 billion in 2017 for third year running", European Audiovisual Observatory, 04/05/2018 https://www.obs.coe.int/ 
Figura 4. Cantidad de espectadores, 2002-2016

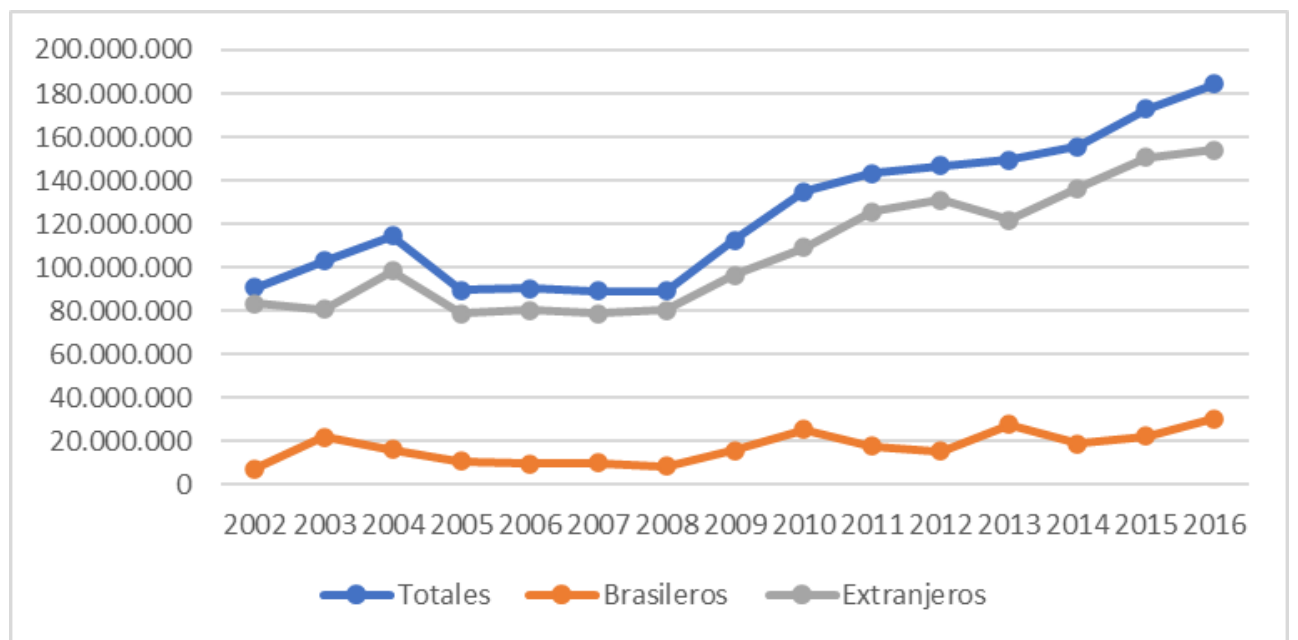

Fuente: OCA-ANCINE

La recaudación va en paralelo a los espectadores dado que es impulsada sobre todo por el cine extranjero (Figura 5). El crecimiento es más acentuado no sólo por el aumento en el precio de los tickets, ni tampoco exclusivamente por cuestiones generales de la economía local (las fluctuaciones de la moneda, inflación, devaluación, etc.), sino también por el hecho de que en los últimos años irrumpió el cine 3D como nuevo modelo de negocios, ya que tiene un precio de ticket más caro que el resto.

Figura 5. Recaudación, 2002-2016

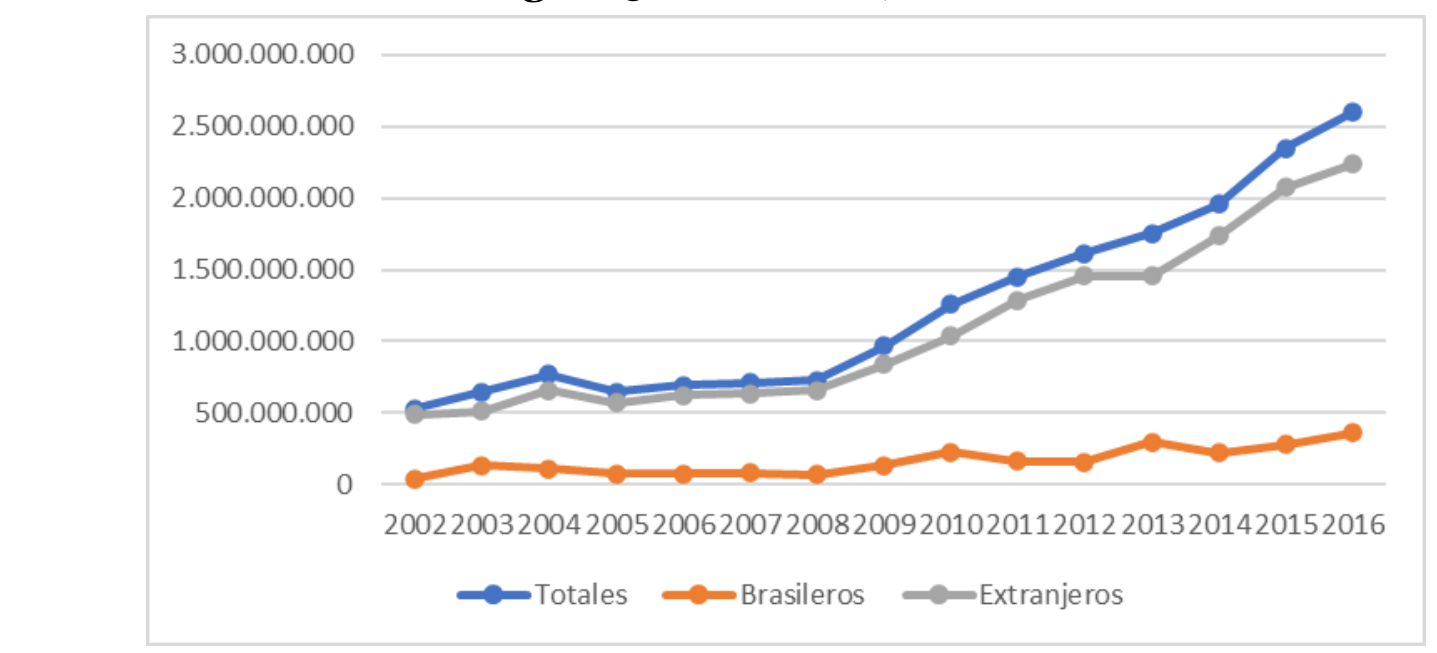

Fuente: OCA-ANCINE 
En la Figura 6 se puede observar la evolución relativa de las tres variables analizadas: estrenos, espectadores y recaudación. Allí se manifiesta muy claramente que el crecimiento de la producción local no ha sido acompañado por el consumo y la recaudación. O, en otras palabras, que el aumento en el volumen de producción no se traduce - al menos no significativamente- en un crecimiento de la cuota de mercado local. El dato se refuerza al constatar que entre 2002 y 2016 el promedio del market share del cine extranjero ha sido del $86 \%$ en términos de espectadores. Como en gran parte del planeta, la expresión "cine extranjero" alude principalmente al cine de Hollywood y sólo en una mínima parte al resto de los cines "nacionales"3.

Figura 6. Cuota de mercado local: estrenos, espectadores y recaudación

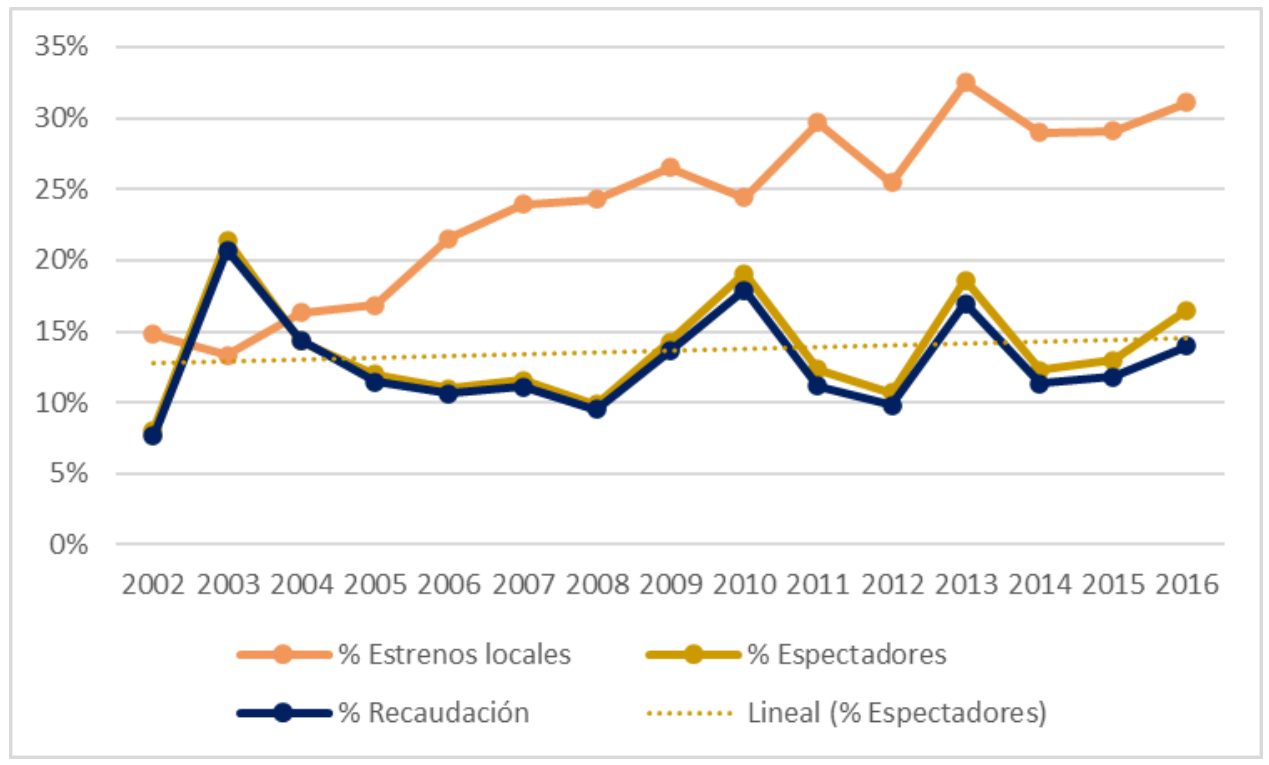

Fuente: elaboración propia en base a OCA-ANCINE

En este contexto, el análisis será orientado a partir de un conjunto de interrogantes: ¿̇cuál es la presencia del cine argentino en el mercado exhibidor de Brasil? ¿En qué medida se trata 
de películas íntegramente argentinas o coproducciones entre Argentina y Brasil? ¿La coproducción con Brasil ha impulsado el estreno de otras películas argentinas? Finalmente, ¿cuál es la performance, en términos de espectadores y recaudación, de los films de origen argentino?

\subsection{Brasil y Argentina en los procesos de integración regional: Ibermedia y la RECAM}

Los lazos e intercambios entre Argentina y Brasil se han fortalecido a partir de los procesos de integración regional. Por eso a continuación se hará una breve referencia al Programa Ibermedia y a la RECAM4.

En lo que respecta a Ibermedia, Brasil es el segundo mayor aportante y receptor del presupuesto, sólo superado por España5 (Tabla 1). Desde la puesta en marcha del programa, Brasil aportó el 12\% y recibió el 10\% del total. De ello se desprende también que Brasil es junto con España el único país que recibe menos de lo que aporta. Argentina, en cambio, es el cuarto mayor aportante y el tercer mayor beneficiario.

4 Para un abordaje en profundidad de la integración iberoamericana se recomiendan Falicov (2012) y de Mora Jiménez (2009); sobre la experiencia mercosureña, Moguillansky (2016).

5 El protagonismo de España es el aspecto más conflictivo de Ibermedia. Por un lado, porque remite al pasado colonial y expresa intenciones diplomáticas que este país tiene desde los años '3o; por el otro, porque -más allá de lo económicoEspaña se beneficia en términos de diversidad cultural (González, 2018). 
Tabla 1. Programa Ibermedia. Fondos aportados/recibidos por país, 1998-2016

\begin{tabular}{|l|l|l|l|l|l|}
\hline País & Aportado & Recibido & Aportado & Recibido \\
\hline Argentina & $\$ 6.099 .956$ & $\$ 8.950 .823$ & $7 \%$ & $10 \%$ \\
\hline Bolivia & $\$ 1.699 .980$ & $\$ 2.989 .976$ & $2 \%$ & $3 \%$ \\
\hline Brasil & $\$ 10.842 .947$ & $\$$ & 9.124 .689 & $12 \%$ & $10 \%$ \\
\hline Chile & $\$ 2.447 .634$ & $\$$ & 4.892 .869 & $3 \%$ & $5 \%$ \\
\hline Colombia & $\$ 2.644 .885$ & $\$ 5.494 .641$ & $3 \%$ & $6 \%$ \\
\hline Costa Rica & $\$ 1.100 .000$ & $\$ 2.044 .677$ & $1 \%$ & $2 \%$ \\
\hline Cuba & $\$ 2.301 .136$ & $\$ 4.276 .669$ & $2 \%$ & $5 \%$ \\
\hline Ecuador & $\$ 1.319 .273$ & $\$ 2.424 .884$ & $1 \%$ & $3 \%$ \\
\hline España & $\$ 37.523 .205$ & $\$ 15.721 .682$ & $40 \%$ & $17 \%$ \\
\hline Guatemala & $\$ 100.000$ & $\$$ & 415.000 & $0 \%$ & $0 \%$ \\
\hline México & $\$ 6.506 .192$ & $\$ 6.831 .964$ & $7 \%$ & $8 \%$ \\
\hline Panamá & $\$ 1.375 .000$ & $\$ 2.701 .533$ & $1 \%$ & $3 \%$ \\
\hline Paraguay & $\$ 400.000$ & $\$$ & 600.000 & $0 \%$ & $1 \%$ \\
\hline Perú & $\$ 2.117 .388$ & $\$ 4.174 .921$ & $2 \%$ & $5 \%$ \\
\hline Portugal & $\$ 4.850 .000$ & $\$ 5.297 .513$ & $5 \%$ & $6 \%$ \\
\hline Puerto Rico & $\$ 1.800 .000$ & $\$ 1.986 .999$ & $2 \%$ & $2 \%$ \\
\hline Rep. & $\$ 1.075 .000$ & $\$ 1.445 .709$ & $1 \%$ & $2 \%$ \\
\hline Dominicana & $\$ 2.375 .000$ & $\$ 4.345 .446$ & $3 \%$ & $5 \%$ \\
\hline Uruguay & $\$ 6.112 .094$ & $\$ 6.450 .749$ & $7 \%$ & $7 \%$ \\
\hline Venezuela & $\$ 92.689 .689$ & $\$ 90.170 .744$ & $100 \%$ & $100 \%$ \\
\hline TOTAL & $\$$ & & &
\end{tabular}

Fuente: elaboración propia en base a Ibermedia.

Si bien Ibermedia se presenta como un programa integral, lo cierto es que sus esfuerzos se han concentrado en la fase productiva (coproducción y desarrollo de proyectos), en detrimento de la distribución y exhibición (Falicov, 2012; Paz, 2010), que son los eslabones decisivos de la cadena de valor ${ }^{6}$.

6 Sólo el 4\% del presupuesto de ANCINE va a la distribución, pero hay intenciones de llevar ese porcentaje al 25\%. Ver: https://oglobo.globo.com/cultura/filmes/presidente-da-ancine-vai-priorizar-investimento-na-distribuicao-de-filmes-em2018-22174265 
Si se analiza la cantidad de proyectos presentados, surge que España ha sido el país más activo, seguido por Argentina, Colombia y Brasil (Figura 7). Esto refleja el interés que estos países tienen por impulsar la integración regional y sacar provecho de su potencial.

Figura 7. Programa Ibermedia. Cantidad de proyectos presentados, países seleccionados,

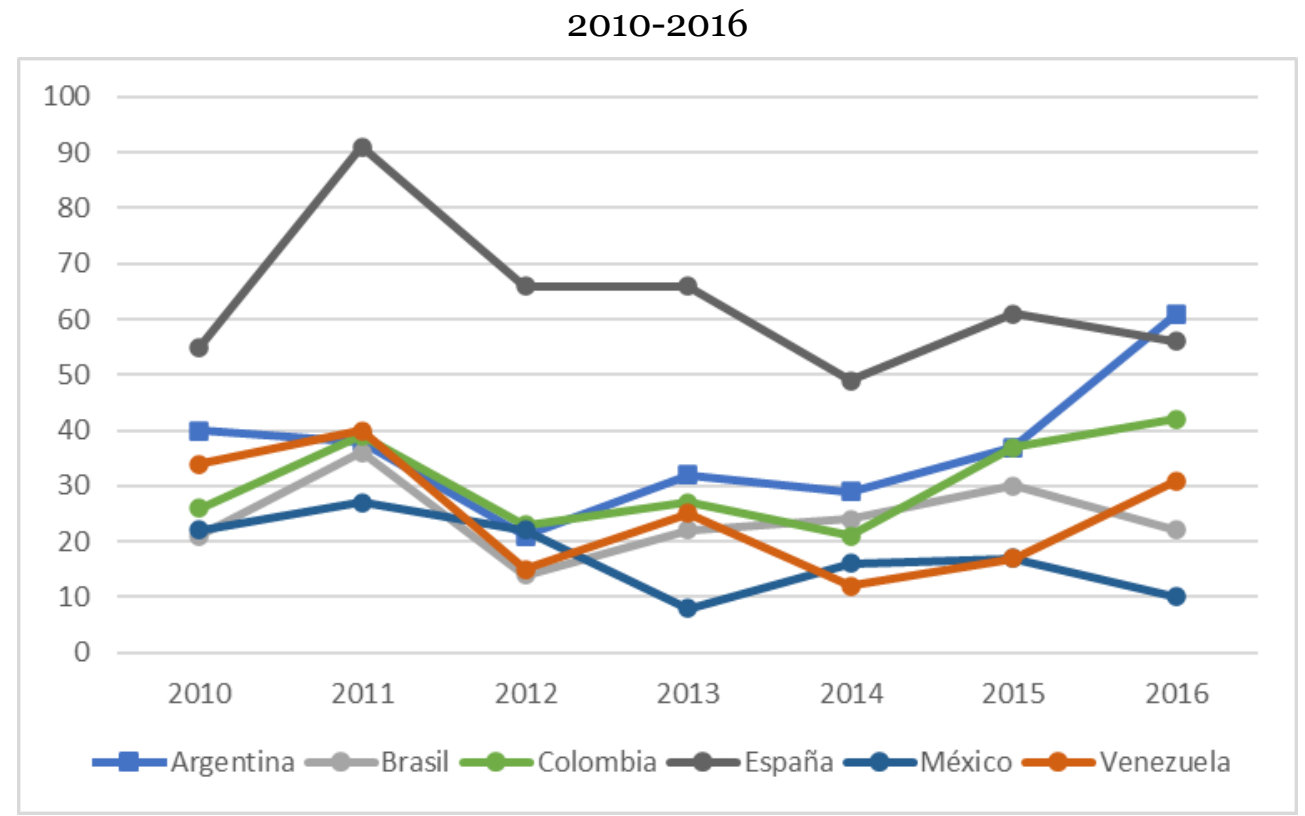

Fuente: elaboración propia en base a Ibermedia.

Otro bloque regional que impulsa políticas cinematográficas tendientes a la integración es el Mercosur, a través de la RECAM (Reunión Especializada de Autoridades Cinematográficas y Audiovisuales del Mercosur). Este organismo surge en el marco más amplio de una integración comercial y política del Mercosur7.

7 El Mercado Común del Sur fue fundado en 1991 por Argentina, Brasil, Paraguay y Uruguay. Desde sus inicios se caracterizó por el énfasis comercial de la integración; no obstante, a partir de la firma del Consenso de Buenos Aires (2003), impulsado por Lula da Silva y Néstor Kirchner, la integración cobró un mayor carácter político y, de esta manera, el bloque puso de manifiesto una reorientación ideológica en abierta confrontación con el carácter neoliberal de la primera etapa. En el ámbito cinematográfico, si bien se registran algunas experiencias que datan desde principios de la década del '9o, éstas eran de un carácter aislado y con escaso impacto en las industrias audiovisuales de la región. La ruptura que se produce a partir de 2003 representa para el cine la constitución de una institucionalidad específica que reconoce la importancia de la dimensión 
En los últimos años esta integración se ha hecho cada vez más palpable, tal como puede observarse en los indicadores cualitativos y cuantitativos presentados por Marina Moguillansky: la Figura 8 muestra cómo los países del bloque aumentaron la exportación intrarregional (Argentina representa dos tercios de lo exportado), mientras que la Tabla 2 muestra distintas dimensiones que dan cuenta de la integración. También resulta relevante subrayar que el bloque ha desplegado su propia Red de Salas Digitales (Carvalho, 2018), orientada exclusivamente a la exhibición de cine mercosureño, a partir de un catálogo de películas seleccionado específicamente.

Figura 8. Evolución de los estrenos mercosureños no nacionales

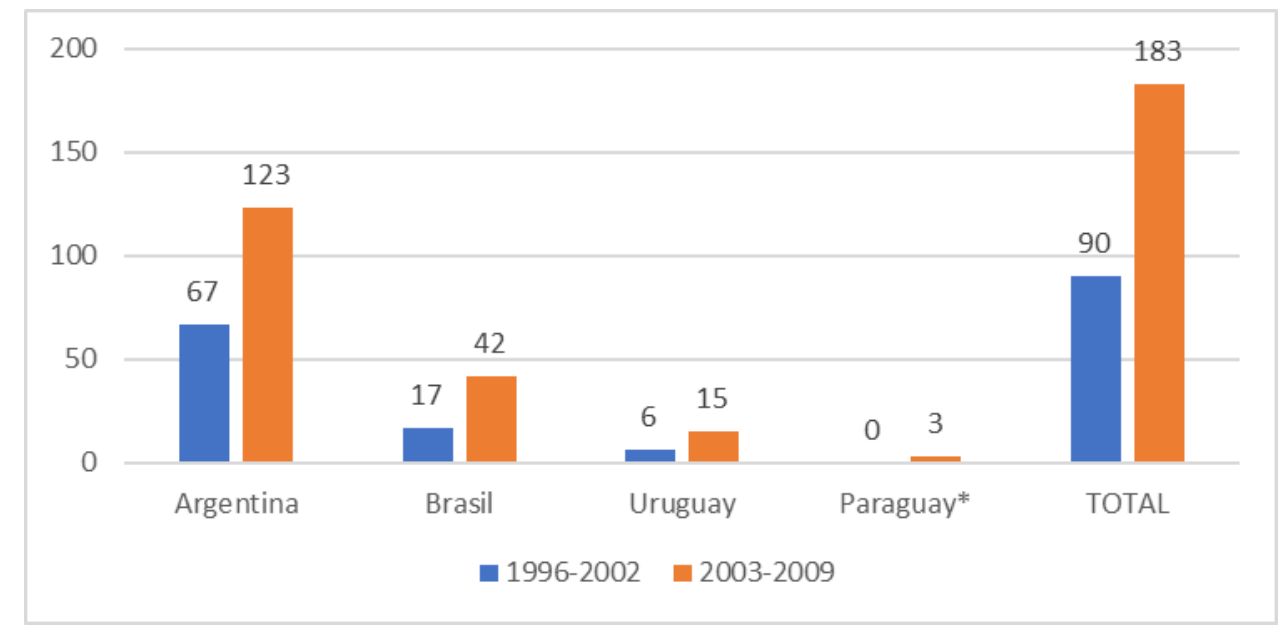

Fuente: Moguillansky (2016)

simbólica de la integración. Los cambios políticos más recientes, sobre todo en Brasil y Argentina, suponen una nueva reorientación del Mercosur. 
Tabla 2. Evolución de la integración cinematográfica en el Mercosur

\begin{tabular}{|c|c|c|c|c|}
\hline & 1991-1995 & 1996-2002 & $2003-2009$ & $2010-2014$ \\
\hline & $\begin{array}{c}\text { Transición a la } \\
\text { Unión } \\
\text { Aduanera }\end{array}$ & $\begin{array}{c}\text { Consolidación } \\
\text { neoliberal }\end{array}$ & $\begin{array}{c}\text { Integración } \\
\text { posliberal }\end{array}$ & $\begin{array}{c}\text { Políticas } \\
\text { regionales de } \\
\text { cine }\end{array}$ \\
\hline $\begin{array}{l}\text { Coproducciones } \\
\text { (promedio } \\
\text { anual) }\end{array}$ & 0,5 & 2 & 6,6 & 9,6 \\
\hline $\begin{array}{c}\text { Estrenos } \\
\text { cruzados } \\
\text { (promedio } \\
\text { anual) }\end{array}$ & 4 & 15 & 26 & 32 \\
\hline $\begin{array}{l}\text { Políticas de } \\
\text { cine }\end{array}$ & $\begin{array}{l}\text { Primeras } \\
\text { muestras }\end{array}$ & $\begin{array}{c}\text { Seminarios y } \\
\text { festivales. Oficina } \\
\text { del Mercosur }\end{array}$ & $\begin{array}{c}\text { Políticas } \\
\text { bilaterales } \\
\text { RECAM. }\end{array}$ & $\begin{array}{c}\text { Programa } \\
\text { Mercosur } \\
\text { Audiovisual }\end{array}$ \\
\hline
\end{tabular}

Fuente: Moguillansky (2015)

La suma de ambas experiencias, Ibermedia y la RECAM, genera condiciones que favorecen notablemente las relaciones entre Brasil y Argentina, lo cual fortalece y a la vez es resultado de una integración regional creciente: "desde la vigencia de Ibermedia, la gran mayoría de las coproducciones registradas entre países del MERCOSUR cuenta con algún tipo de apoyo por parte de este programa, ya sea en el desarrollo de guion, en los fondos de coproducción o en la distribución de la película terminada” (Moguillansky, 2016: 38).

\subsection{Las coproducciones internacionales brasileñas}

En las últimas décadas se viene percibiendo a escala global un aumento de la coproducción internacional. Se trata de productos que son transnacionales desde su concepción, con narrativas muchas veces pensadas para una audiencia global y que incluyen actores y/o técnicos de distintos países como condición para obtener el reconocimiento oficial. Esto implica que estas películas tienen los beneficios nacionales de todos los países que 
intervengan, lo cual aumenta las posibilidades de captar fondos (financiamiento) y de asegurar su exhibición en distintos mercados (comercialización y cuota de pantalla) ${ }^{8}$.

En este contexto, no sorprende que en Brasil se registre un "aumento de novos filmes brasileiros realizados com sócios internacionais” (Figueiró, 2017: 22) (Figura 9). Sin duda, esto se explica por la acción conjunta de Ibermedia, la RECAM y los acuerdos bilaterales de coproducción y cooperación.

Figura 9. Evolución de las coproducciones brasileñas, 2005-2016

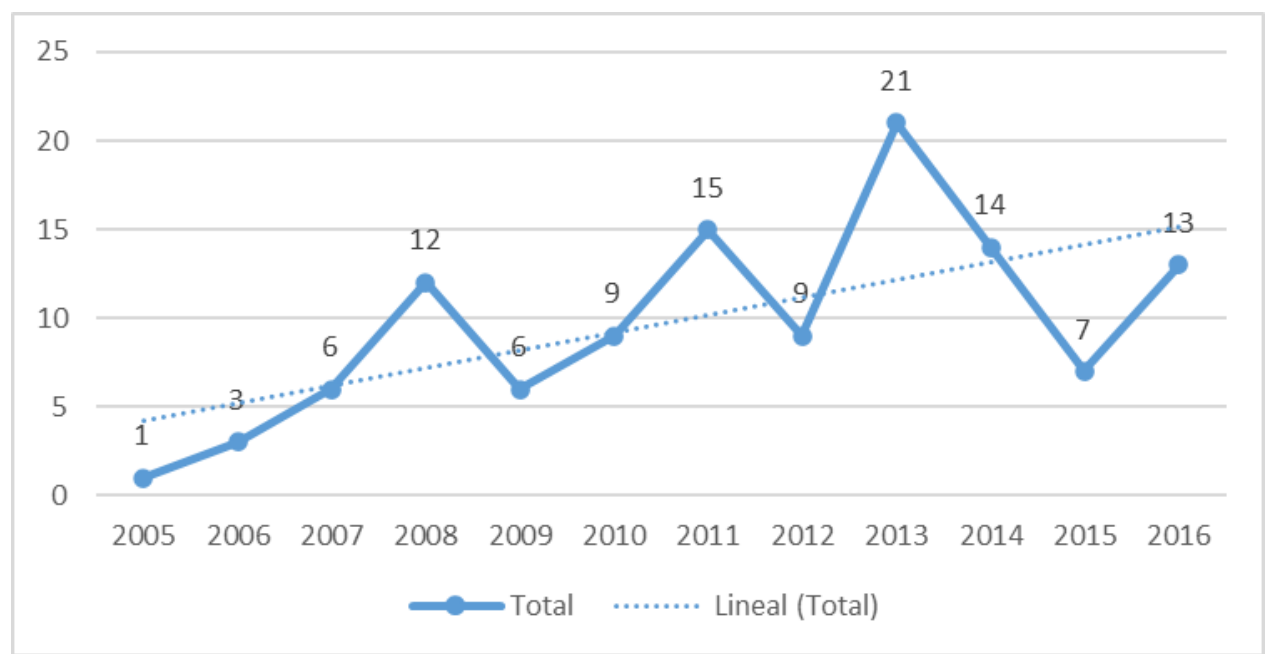

Fuente: OCA-ANCINE

En general, estas coproducciones tienen participación mayoritaria (53\%) brasileña (Figura 10). Esto implica que suele ser una productora brasileña la que encabeza el proyecto y tiene mayor control y participación en la comercialización del film. Esto es indicativo de la intención que tienen los productores y las autoridades cinematográficas de Brasil de internacionalizar su producción para ingresar en otros mercados, lo cual ha tenido como histórica dificultad a la barrera idiomática.

8 Pardo (2007) señala que las ventajas de la coproducción son el financiamiento, el aumento del mercado, el acceso potencial a costos de producción más competitivos, acceso a locaciones foráneas e incluso enriquecimiento cultural; mientras que los riesgos serían la dificultad de producir films de atractivo universal, la complejidad de las negociaciones, el peligro de efectos inflacionarios por el cambio de divisas y la posible pérdida del control creativo sobre el proyecto. 
Moguillansky agrega que esto se debe al sistema de mecenazgo que financia a buena parte del cine brasileño: "ya que a las empresas les importa su imagen en Brasil, les resulta más atractivo financiar películas brasileñas o con participación mayoritaria de Brasil” (2016: 71).

Otra interpretación posible es que los socios internacionales de las coproducciones brasileñas consideran demasiado riesgoso o carecen de estímulos para encabezar un proyecto que incluya diálogos en portugués y/o algún otro elemento difícilmente atractivo para un público internacional. En términos estrictamente económicos, el principal beneficio para un socio internacional es el acceso al enorme mercado brasileño, pero probablemente le resulte más conveniente dejar la comercialización en manos de la parte local, que tiene el know how específico.

Figura 10. Participación de Brasil en las coproducciones, acumulado 2005-2016

Fuente: OCA-ANCINE

Por eso, no es casual que el principal socio sea Portugal, país con el que Brasil comparte históricos vínculos y el idioma (Figura 11). Sí es interesante observar que Argentina aparece en segundo lugar, por encima de activos coproductores europeos (como Francia ${ }^{9}$ o España), y muy por encima de otros países de la región (Chile o Uruguay). 
Figura 11. Principales socios de las coproducciones brasileñas, acumulado 2005-2016

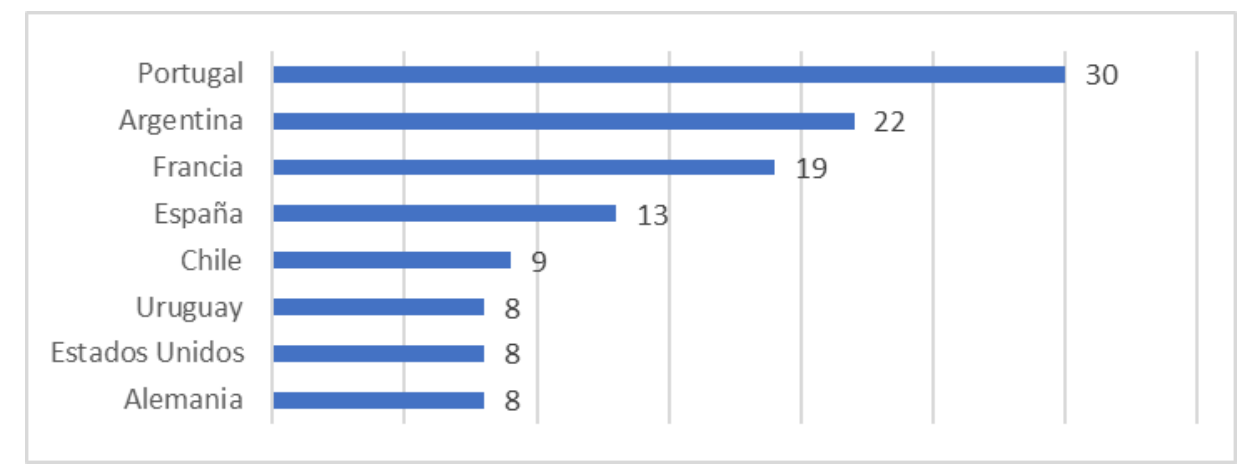

Fuente: OCA-ANCINE

Respecto a las empresas que intervinieron a lo largo de este periodo, se observa un alto nivel de dispersión combinado con algunos casos que parecen evidenciar una mayor adopción del sistema de coproducción. Entre 2005-2016, Brasil realizó 117 coproducciones internacionales en las cuales intervinieron 70 productoras brasileñas, de las cuales 10 participaron en 3 o más proyectos. La más activa ha sido Videofilmes Produções Artísticas Ltda (de los hermanos Walter Salles e João Moreira Salles), con un total de 8 films.

Tomando en cuenta estas características del mercado brasileño y sus estrategias de internacionalización, es posible ahora pasar a examinar la presencia y performance del cine argentino en dicho mercado.

\section{LA PARTICIPACIÓN ARGENTINA}

El análisis de la participación argentina en Brasil se hará a partir de una primera distinción entre las coproducciones argentino-brasileñas y el resto de las películas de nacionalidad argentina, para una posterior comparación. Esta distinción no es meramente analítica, sino que a ojos de los funcionarios y los institutos de cine se trata de objetos jurídicamente distintos.

\subsection{Coproducciones}

Si bien históricamente hubo vínculos entre las cinematografías de ambos países (Autran, 2016; Gil, 2014), sólo en las últimas décadas se formalizó la relación. El Acuerdo de 
Coproducción entre Argentina y Brasil se comenzó a implementar en $1995^{10}$ y estipula qué características deberá tener un proyecto para ser reconocido oficialmente por las partes como una coproducción argentino-brasileña.

Con el cambio de siglo, la relación fue escalando hasta alcanzar mayores niveles de integración. En 2003 se puso en marcha un Acuerdo de Co-distribución entre el INCAA y ANCINE, que contemplaba un subsidio en dinero a los distribuidores para que comercialicen títulos argentinos en Brasil y títulos brasileños en Argentina; no obstante, por diversas dificultades este acuerdo fue discontinuado: "lo llamativo es que una vez concluido dicho acuerdo todavía continúa (...) la exportación de cine argentino hacia Brasil, ahora en función del interés de los distribuidores, exhibidores y espectadores de cine" (Moguillansky, 2016: 76). En 2011 se firmó un Acuerdo de Cooperación, en el marco del cual se realizan convocatorias específicas para financiar proyectos de ambas nacionalidades: desde entonces, cuatro coproducciones argentino-brasileñas por año reciben fondos no reembolsables.

Datos de ANCINE referidos específicamente a coproducciones señalan que entre 2005 y 2016 se realizaron $21^{11}$ películas con participación de Argentina y Brasil (Figura 12). En total, esto representa el $\mathbf{1 8 \%}$ de las coproducciones brasileñas durante todo el periodo. Tal como había sido señalado anteriormente, Argentina es el segundo socio más importante de Brasil.

10 Si bien el Acuerdo se firmó en 1988, hubo que esperar siete años para ponerlo en marcha (INCAA, 1995). Hubo un antecedente, el "Convenio sobre Coproducción Cinematográfica" firmado en 1968, pero aprobado recién en 1981 (ver Infoleg y Filme Cultura, 1968).

11 Las fuentes de ANCINE señalan un total de 22 coproducciones (ver Figura 11), pero en el listado figuran 21. Ante el error de origen, se optó por tomar la cantidad del listado, dado que tiene información más detallada (ver Anexo). 
Figura 12. Coproducciones de Brasil y detalle para las coproducciones con Argentina, 2005-2016

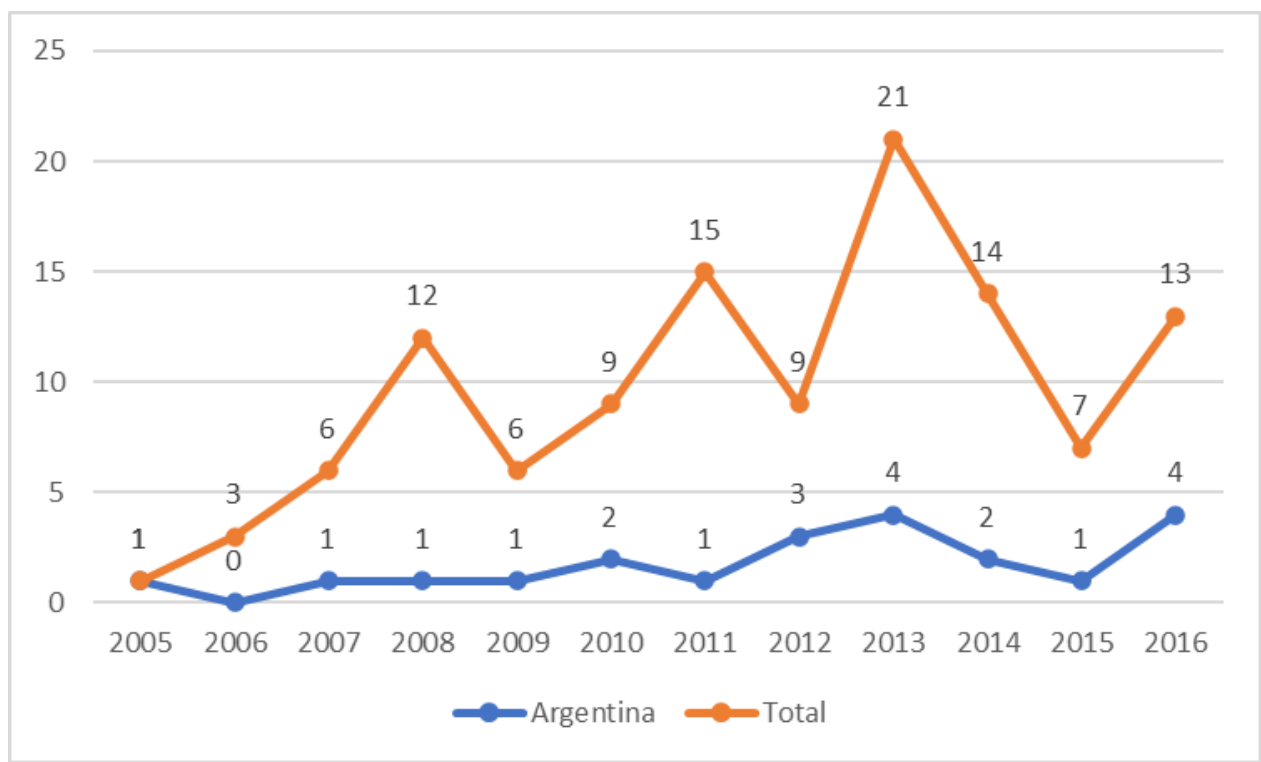

Fuente: elaboración propia en base a OCA-ANCINE

Sólo un tercio de las coproducciones argentino-brasileñas incluyen la participación de un tercero (Portugal, Chile y Francia en dos oportunidades; Estados Unidos, México y España en una), es decir, dos de cada tres han sido exclusivamente bipartitas (Tabla 3). Si bien más de la mitad tienen a Brasil como socio mayoritario (Figura 13), en general la relación es bastante equilibrada (sobre todo si se la contrasta con los datos de la Figura 10).

Tabla 3. Coproducciones con participación argentina, brasileña y de terceros

Fuente: elaboración propia en base a OCA-ANCINE

\begin{tabular}{|c|c|c|}
\hline Países socios & Films & \% \\
\hline Brasil y Argentina & 14 & $67 \%$ \\
\hline Brasil, Argentina y Portugal & 2 & $10 \%$ \\
\hline Brasil, Argentina y Chile & 2 & $10 \%$ \\
\hline Brasil, Argentina y otros & 3 & $14 \%$ \\
\hline Total & 21 & $100 \%$ \\
\hline
\end{tabular}


Figura 13. Participación brasileña en las coproducciones con Argentina

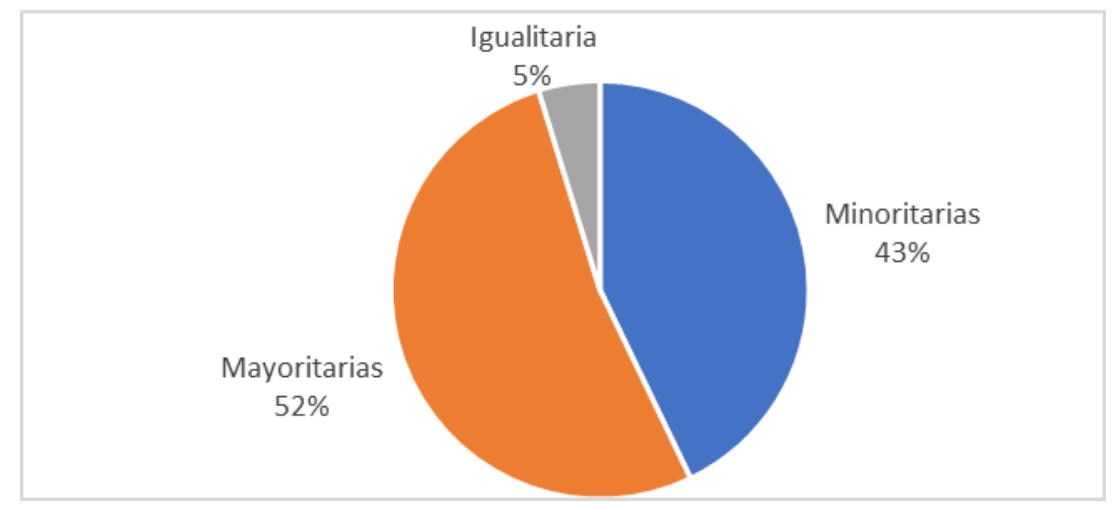

Fuente: OCA-ANCINE

En total, estas 21 coproducciones con participación argentina tuvieron 757.164 espectadores, lo cual da un promedio de 36.000 espectadores por film y 63.000 por año. Tal como puede observarse en el siguiente gráfico (Figura 14), a pesar de ciertas oscilaciones, la performance de estas coproducciones marca una tendencia general ascendente. 
Figura 14. Performance de las coproducciones entre Argentina y Brasil

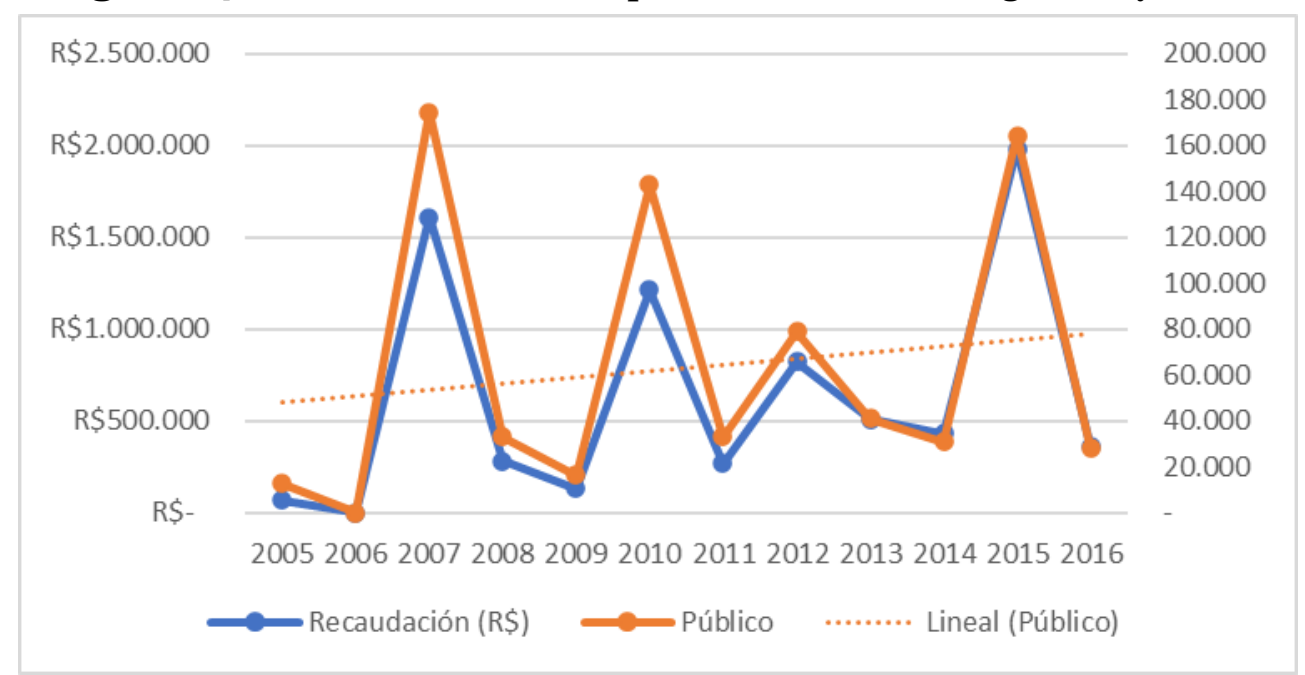

Fuente: elaboración propia en base a OCA-ANCINE

La recaudación es correlativa al público porque el cine argentino prácticamente no hace producciones 3D o 4D ni tampoco - esto es una suposición - tiene el atractivo para exhibirse en las salas premium (Rud, 2011; Ferraz y Cruz, 2012). Es decir, a diferencia de los "tanques" de Hollywood, el cine argentino no se comercializa con precio de ticket más alto, sino a un precio estándar.

Todos los títulos fueron films de ficción, excepto el documental Café dos Maestros (Miguel Kohan, 2008). Las películas más exitosas en términos de espectadores fueron $O$ Passado (Hector Babenco, 2007), Divã a 2 (Paulo Fontenelle, 2015) y 400 contra 1 - a História do Comando Vermelho (Caco Souza, 2010), ya que son las únicas que superaron los cien mil tickets vendidos; el resto se encuentra por debajo de los cuarenta mil. No casualmente, son las películas que tuvieron un mayor apoyo en su lanzamiento, es decir, se estrenaron en una mayor cantidad de salas: 50 salas en el primer caso, 315 en el segundo y 76 en el tercero.

Si se pondera por lanzamiento, habría que decir que la mejor performance de las tres fue claramente la primera, ya que tuvo la mayor cantidad de espectadores con la menor cantidad de salas. De hecho, este indicador ponderado señala otros dos films con un mejor coeficiente: Violeta Foi Para o Céu (Andrés Wood, 2012) y la mencionada Café dos Maestros, ambas con una mayor cantidad de espectadores por salas de lanzamiento que O Passado. Esto señala la relevancia de que la estrategia de lanzamiento sea acorde al tipo de película. Por ejemplo, 
Violeta Foi Para o Céu (coproducción entre Argentina, Brasil y Chile) se estrenó en sólo 10 salas y llevó a 37.243 espectadores. En otras palabras: un lanzamiento masivo de 300 salas no asegura el éxito comercial; el "éxito comercial" puede obtenerse apuntando a público específicos, a nichos.

En cuanto a las empresas, hay algunas productoras brasileñas que participaron en más de un proyecto: Videofilmes Produções Artísticas Ltda. (3 films), Bananeira Filmes (3), Telecine Programação de Filmes Ltda. (2), Acorde Comunicacao Ltda. (2), Panda Filmes Ltda (2), Taiga Filmes e Vídeo Ltda. (2). Por el lado de las productoras argentinas, hay algunas que hicieron dos proyectos: Aleph Media S. A., Americine S. R. L., Cepa Audiovisual, K\&S Films, Lita Stantic; el resto sólo participó en una. También hay alguna recurrencia en la comercialización, ya que se destacan tres distribuidoras: Imovision ( 5 títulos), Videofilmes (productora que distribuye dos de las tres películas que produjo) e Imagem (2).

\subsection{Películas "argentinas"}

A pesar de la importancia y el peso creciente de las coproducciones argentino-brasileñas, el dato sorprendente es que son ampliamente superadas en cantidad por las películas argentinas sin participación brasileña. Para proceder en el análisis resulta necesario establecer esta distinción. En adelante se considerará como "argentinas" a todas las películas de dicha nacionalidad, excepto a las que tienen participación brasileña. Estas películas no siempre son íntegramente argentinas, sino que muchas veces son coproducciones con países distintos a Brasil.

En total, se estrenaron 70 películas "argentinas" entre 2009 y 2016, las cuales obtuvieron un total de 2.774.449 espectadores (Tabla 4). Para dimensionar esta presencia, puede señalarse que en el mismo periodo se estrenaron 2984 films totales, lo cual significa que el porcentaje de películas "argentinas" es de 2,3\% (y no de 1,2\% como mostraban los datos preliminares de la Figura 3). Otro dato señala que se estrenaron 858 producciones brasileñas, de las cuales 94 fueron coproducciones internacionales (18 tuvieron participación argentina). Esto significa que las películas “argentinas” obtuvieron un promedio de 322.681 espectadores por año y 36.878 por film. 
Tabla 4. Estrenos y performances de las películas argentinas (no-brasileñas)

\begin{tabular}{|l|l|lr|l|l|}
\hline $\begin{array}{l}\text { Año de } \\
\text { exhibición }\end{array}$ & Espectadores & Recaudación & $\begin{array}{l}\text { Estrenos } \\
\text { únicos }\end{array}{ }^{12}$ & $\begin{array}{l}\text { Espectadores } \\
\text { por film }\end{array}$ \\
\hline 2009 & 84.049 & R $\$$ & $698.811,35$ & 12 & 7.004 \\
\hline 2010 & 387.277 & $\mathrm{R} \$$ & $3.848 .949,92$ & 8 & 48.410 \\
\hline 2011 & 605.962 & $\mathrm{R} \$$ & $6.780 .163,19$ & 7 & 86.566 \\
\hline 2012 & 134.009 & $\mathrm{R} \$$ & $1.469 .611,88$ & 6 & 22.335 \\
\hline 2013 & 182.151 & $\mathrm{R} \$ 2.196 .997,91$ & 7 & 26.022 \\
\hline 2014 & 505.136 & $\mathrm{R} \$$ & $7.217 .302,10$ & 7 & 72.162 \\
\hline 2015 & 327.141 & $\mathrm{R} \$ 4.658 .797,57$ & 11 & 29.740 \\
\hline 2016 & $355 \cdot 724$ & $\mathrm{R} \$ 5.508 .066,27$ & 12 & 29.644 \\
\hline Total & 2.581 .449 & $\mathrm{R} \$ 32.378 .700,19$ & 70 & 36.878 \\
\hline Promedios & 322.681 & $\mathrm{R} \$ 4.047 .338$ & 9 & \\
\hline
\end{tabular}

Fuente: elaboración propia en base a OCA-ANCINE

Ahora bien, ¿cuál es verdaderamente la relación entre estas películas y las coproducciones argentino-brasileñas? ¿La distinción entre unas y otras es superflua o, por el contrario, tiene implicancias y permite explicar una presencia y performance diferenciada entre los dos tipos de películas de nacionalidad argentina?

\subsection{Comparación entre las coproducciones y el resto}

La comparación se acota al periodo 2009-2016 dado que es el único periodo en el cual hay datos disponibles para ambas variables (Figura 15). El primer dato por destacar es que la presencia de películas "argentinas" es siempre superior a las coproducciones. 
Figura 15. Estrenos “argentinos” y coproducciones entre ambos países

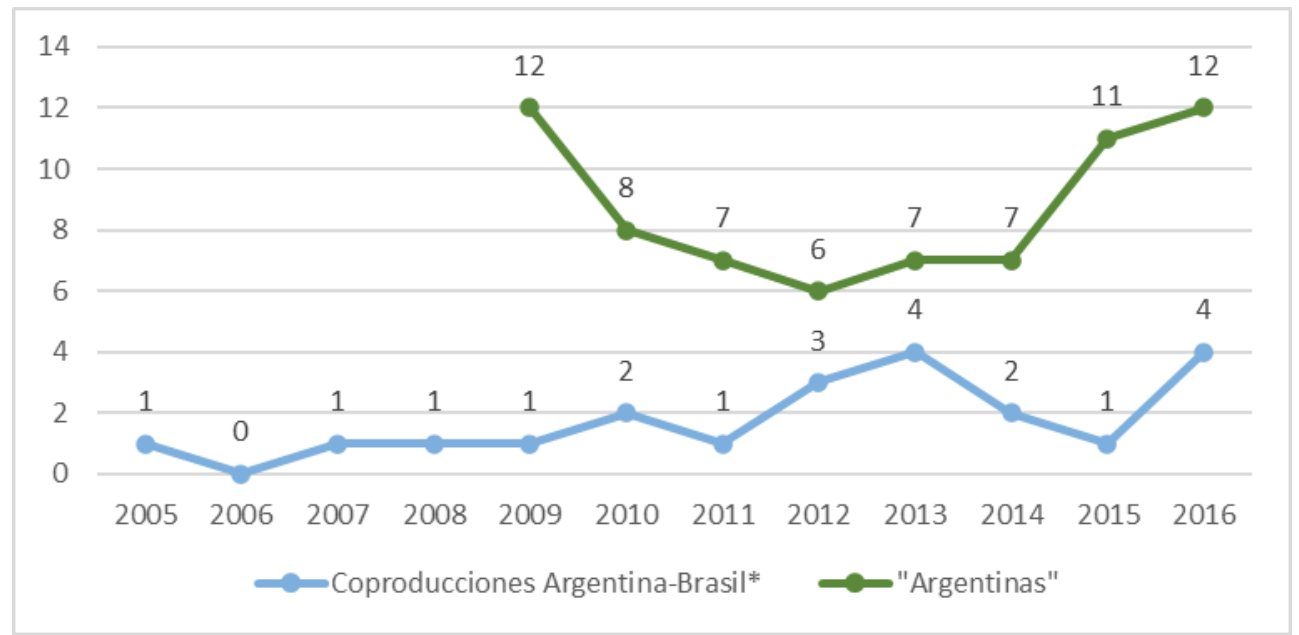

Fuente: elaboración propia en base a OCA-ANCINE

La misma relación se traslada a la performance, es decir, a la cantidad de espectadores y a la recaudación que logran todas esas películas en el mercado brasileño (Figura 16). Por supuesto, esta mejor performance está estrechamente vinculada a la "superioridad" en volumen de películas.

Figura 16. Comparación entre la performance de las películas “argentinas” y las coproducciones entre Argentina y Brasil

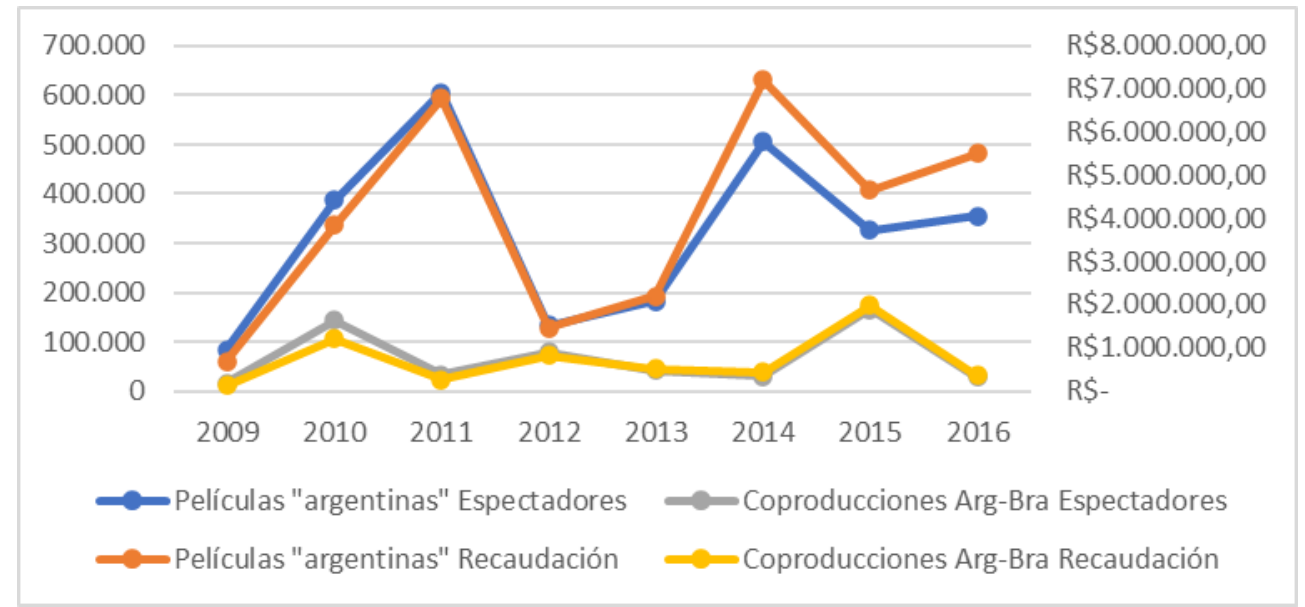

Fuente: elaboración propia en base a OCA-ANCINE 
¿Cómo se explican las oscilaciones en las performances de las películas? En primer lugar, podría argumentarse que están asociadas al volumen de estrenos: cuantas más películas se estrenan, es esperable que lleven más espectadores. No obstante, hay una característica general en el recorrido comercial de las películas en todos los mercados del mundo: la concentración del público en unos pocos títulos. Y esto es válido tanto para el cine de Hollywood como para los cines locales (en Argentina es habitual que dos o tres "tanques nacionales" concentren cerca del $90 \%$ de los espectadores de cine nacional). Nazareno (2017) señala una diferencia importante entre la internacionalización del cine argentino y el brasileño: el primero exporta películas que primero han sido exitosas en el mercado local. Así, por ejemplo, Relatos salvajes (Damián Szifrón, estrenada en octubre de 2014) es una de las películas más vistas en la historia de la Argentina, y en Brasil fue vista por 305.793 espectadores en 2014 (lo cual explica el pico de ese año) y por 157.873 en 2015. Es decir: esta única película representa cerca del 60\% de los espectadores de cine argentino en Brasil en 2014 y más del 50\% en 2015. Desde este punto de vista, la oscilación no es expresión de una performance errática sino, más bien, expresión natural de la comercialización de cines como el argentino, que en su propio mercado despliegan un comportamiento semejante.

No obstante, en términos relativos se hace evidente que las coproducciones tienen una mejor performance que el resto (Tabla 5). Esto se constata al observar que prácticamente duplican en cantidad de espectadores por film a las películas "argentinas".

Tabla 5. Comparación entre la presencia y performance de las películas "argentinas" y las coproducciones entre Argentina y Brasil (2009-2016)

\begin{tabular}{|l|l|l|}
\hline & Coproducciones Arg-Bra & "Argentinas" \\
\hline Títulos & 18 & 70 \\
\hline Títulos por año & 2,25 & 8,75 \\
\hline Espectadores & 1.293 .684 & 2.581 .449 \\
\hline Espectadores por año & 161.711 & 322.681 \\
\hline Espectadores por film & 71.871 & 36.878 \\
\hline
\end{tabular}

Fuente: elaboración propia en base a OCA-ANCINE

En síntesis: si se suman todas las películas de nacionalidad argentina, se obtiene que en promedio se estrenan 11 largometrajes argentinos por año, que son vistos por medio millón de brasileños (lo cual coincide con las estimaciones de Nazareno, 2017), aproximadamente. 
Esto representa una cuota de mercado del $0,3 \%$. Y comparado con los tickets que venden todas las películas argentinas en su propio mercado, esto representa aproximadamente el $10 \%$.

¿Hay razones que explican el mayor éxito comercial de las coproducciones? Puede argumentarse que las coproducciones incluyen actores brasileños, muchas veces son rodadas en ese país, incluso pueden ser habladas en portugués y, cuando se dan todas esas condiciones, tienen las características de una película íntegramente local. Parafraseando a Moguillansky (2008), las coproducciones pueden estar menos connotadas con rasgos de argentinidad. En contraste, tal como plantea Rodríguez Isaza, el resto de las películas extranjeras (excepto las de Hollywood) "se enfrentan a una mayor barrera para el comercio internacional que aquellas que tienen características ya conocidas por los consumidores” y “ocupan un nicho de mercado, ya que generalmente se perciben como más «difíciles» para los espectadores que no conocen la cultura, los lugares, personajes, actores o incluso el idioma de la película" (2014: 71). Es decir, desde la perspectiva de los espectadores, tal vez las coproducciones tengan mayores posibilidades de escapar a los sistemas clasificatorios (por ejemplo: "cine argentino", "cine de festivales", "cine de autor", etc.) y a los prejuicios que pueden estar asociados ("es más aburrido", "no voy a entender el lenguaje”, etc.). Sin duda, mucho de esto queda por investigar.

\section{REFLEXIONES FINALES}

Los datos muestran que existe un volumen creciente de películas argentinas que tienen estreno comercial en Brasil. Pero además de analizar las cifras, se han analizado los factores que contribuyen a esta situación.

En primer lugar, se señaló la expansión que el mercado cinematográfico brasileño experimentó tras el cambio de siglo. Concretamente: entre 2002 y 2016 prácticamente se duplicó la cantidad de salas y de espectadores en términos absolutos. No obstante, sólo en una mínima parte el cine brasileño logró capturar este crecimiento. Segundo, se hizo referencia a los procesos de integración regional: Argentina y Brasil lideran la experiencia del Mercosur (RECAM) y además se encuentran entre los países más activos del Programa Ibermedia. El interés que demuestran por estos procesos redunda en un incremento de los flujos de intercambio entre ambos, en una y otra dirección. En tercer lugar, a ello hay que sumar las políticas específicas que los vinculan entre sí: el acuerdo de coproducción de 1988, el de codistribución de 2003 y el de cooperación en 2011. A pesar de la aplicación dispar de 
estos instrumentos, sin duda éstos explican en buena medida por qué la Argentina es el principal socio de coproducción de Brasil, sólo por detrás de Portugal (el socio "natural”, si se obedece a la proximidad lingüística) y por encima de Francia y España.

En síntesis, no se podrá comprender la presencia del cine argentino en Brasil si no es a partir de un conjunto de factores que se articulan de manera compleja: el dinamismo del mercado local; la decisión política y estratégica de ambos países de participar activamente en los espacios regionales; y los acuerdos bilaterales que explícitamente buscan impulsar los intercambios. Cada uno de estos factores es determinante y, a la vez, potencia a los otros dos.

Por otro lado, los resultados muestran que, aunque se estrenan más películas "argentinas" (sin participación brasileña) que coproducciones entre ambos países, en términos relativos estas últimas tienen un mejor recorrido comercial, ya que prácticamente duplican la cantidad de espectadores por film de las otras. Esto habla de una diferencia de "naturaleza" entre ambos tipos de películas: la coproducción es, desde su gestación, un producto global. Tiene al menos dos nacionalidades, lo cual implica no sólo que hay al menos dos productoras de distintos países apoyando el proyecto, sino también al menos dos institutos de cine que reconocen la respectiva "nacionalidad" y - por lo tanto- la habilitan a obtener los beneficios de cada país (créditos y subsidios, cuota de pantalla, etc.). Más aún: muchas veces, a ojos del espectador, una coproducción internacional puede ser vista como una película íntegramente nacional. Pero, como se argumentó, la diferencia entre estos dos tipos de películas no es meramente analítica, sino que a ojos de los funcionarios y los institutos de cine son vistas como jurídicamente distintas. En suma: la coproducción internacional es un fenómeno complejo, necesariamente transnacional y por ello tiene muchas más facilidades y motivaciones para incursionar en el circuito comercial internacional.

Finalmente, surge un interrogante que difícilmente puede ser dejado de lado: ¿de qué modo el giro político de ambos países en los últimos años puede impactar en la integración, la cooperación y la competencia de los cines de Argentina y Brasil? No es sencillo responder de manera contundente, pero sin duda pueden señalarse algunos puntos. En primer lugar, la coincidencia histórica de los gobiernos de centro izquierda en ambos países (Néstor Kirchner y Cristina Fernández en Argentina, Luiz Inácio Lula da Silva y Dilma Rousseff en Brasil) impulsó un crecimiento notable en las cinematografías de cada país. Segundo, la afinidad entre ambos se trasladó al espacio regional, en particular en el bloque del Mercosur, 
donde se hizo evidente una reorientación política que en el campo del cine tuvo una consecuencia muy concreta: la creación de la RECAM.

Si bien la historia es compleja, irrepetible, impredecible y está atada a contingencias, es indudable que el contragiro a la derecha que experimenta la región desde 2015 configura un escenario distinto. Habrá que ver cómo esto afecta a las políticas cinematográficas de cada país, a los acuerdos bilaterales de cooperación y a los procesos de integración regional. Habrá que seguir de cerca estas cuestiones porque la región se encuentra avanzando en una dirección opuesta a la que - no sin dificultades - favoreció el desarrollo y la integración de los cines de Argentina y Brasil. 


\section{Referencias bibliográficas}

AMANCIO, T. (2014): Argentina-Brasil no cinema: diálogos. Niterói: Editora da UFF.

AUTRAN, A. (2016): A guerra gaúcha: o Cinema argentino no Brasil (1935 - 1945). Intercom: Revista Brasileira de Ciências da Comunicação, 39 (1), pp. 139-158. https://doi.org/10.1590/1809-5844201618

BORELLO, J., GONZÁLEZ, L., RUD, L. y YOGUEL, G. (2018): La exportación de cine argentino en el circuito comercial internacional. Prácticas, mercados y políticas. Programa de Investigadores, Secretaría de Comercio, Documento de trabajo no. 26. https://www.argentina.gob.ar/sites/default/files/com inv buenas practicas exportador as 26 010618.pdf

CARVAlHO, M. J. (2018): A Rede de Salas Digitais do MERCOSUL e a promoção da diversidade cultural. Encuentros latinoamericanos, 2 (1).

DAIELLO, J. (2011): Co-produção entre Brasil e Argentina no cinema: o caso do filme Insônia de Beto Souza. Tesina de grado en Comunicação Social, Universidade Federal do Rio Grande do Sul.

DE MORA, R. (2009): Cooperación e integración audiovisual en Iberoamérica. Tesis de doctorado, Universidad Complutense de Madrid.

EUROPEAN AUDIOVISUAL OBSERVATORY (2018): Focus 2017. Paris: Global Rouge.

FALICOV, T. L. (2012): Programa Ibermedia: ¿cine transnacional ibero-americano o relaciones públicas para España? Revista Reflexiones, 91 (1), pp. 299-312.

FERRAZ, T. y CRUZ, L. (2012): Quando o cinema é a maior sofisticação: experiências sensíveis, desejo e práticas de consumo nas salas exibidoras de luxo do Rio de Janeiro. Revista Contracampo, 24 (1), pp. 249-265. DOI: 10.22409/contracampo.v1i24.219

FIGUEIRÓ, B. (2017): As dinâmicas do mercado das coproduções cinematográficas entre Brasil e França. Tesis de Maestría en Imagen y Sonido, Universidade Federal de Sao Carlos. 
FILME CULTURA (1968): "Objetivos comuns: INC Brasil Argentina". Ano II, nº10, 20/07/1968 http://hmg.revista.cultura.gov.br/item/filme-cultura-n-10/

FREIRE, R., y ZAPATA, N. H. A. (2017): Quantas salas de cinema existiram no Brasil? Reflexões sobre a dimensão e características do circuito exibidor brasileiro. Significação: Revista De Cultura Audiovisual, 44 (48), pp. 176-201. DOI: https://doi.org/10.11606/issn.2316-7114.sig.2017.135195

GARCÍA, N. (2011): Comunicación y ciencias sociales: el giro transdisciplinario y la política. Oficios Terrestres, 1 (27), pp. 1-19.

GIL MARIÑO, C. N. (2014): Primeros intercambios entre la industria cinematográfica argentina y brasileña en la década del treinta. AdVersuS. 11 (27), pp. 74-101.

GONZÁLEZ, L. (2015): Exhibición y consumo de cine en la Argentina (1980-2013). La reconfiguración del espectáculo cinematográfico en cifras. Revista Versión, no. 36, pp. 7688. ISSN 2007-5758.

Disponible en:

http://version.xoc.uam.mx/tabla contenido.php?id fasciculo $=710$

GONZÁLEZ, L. (2018): Cruzando el Atlántico: cine argentino en España. Revista Imagofagia: revista de la Asociación Argentina de Estudios de Cine y Audiovisual (ASAECA), no. 17, ISSN N ${ }^{\circ}$ 1852-9550, pp. 41-70.

http://www.asaeca.org/imagofagia/index.php/imagofagia/article/view/1505/1325

Ibermedia. Informes anuales 2006-2016.

INCAA (1995). Acuerdo de Coproducción Cinematográfica suscripto con la República Federativa del Brasil.

http://internacionales.incaa.gov.ar/wp-content/uploads/2013/o7/ACUERDO-

BRASIL.pdf 
InfoLEG, LEY N 22.456 http://servicios.infoleg.gob.ar/infolegInternet/anexos/205000209999/206138/norma.htm

MOGUILLANSKY, M. (2008): La imaginación en cuestión. El cine brasileño en la Argentina desde la creación del Mercosur (1995-2005). Tesis de Maestría en Sociología de la cultura y análisis cultural, IDAES-UNSAM.

MOGUILlANSKY, M. (2014): No los une el amor, sino el dinero. Las coproducciones cinematográficas entre Argentina y Brasil. En: AMANCIO, T. (Coord.): Argentina-Brasil no cinema: diálogos. Niterói: Editora da UFF.

MOGUILLANSKY, M. (2015): La integración cinematográfica en el Mercosur. Una propuesta de periodización. Eptic online: revista electronica internacional de economia política da informaçao, da comuniçao e da cultura, 17 (3), pp. 105-124.

MOGUILLANSKY, M. (2016): Cines del Sur. La integración cinematográfica entre los países del MERCOSUR. Buenos Aires: Imago Mundi.

NAZARENO, C. (2017): Cine Argentino-por que ele é bom... será? Revista Eptic, 19 (3), pp. 41-58.

OCA-ANCINE. Observatório Brasileiro do Cinema e do Audiovisual, Agência Nacional do Cinema: http://oca.ancine.gov.br/

PARDO, A. (2007): Coproducciones internacionales españolas: ¿estrategia financiera o expresión multicultural? Comunicación y sociedad, 20 (2), pp. 133-173.

PAZ, C. (2010): El agotamiento del modelo cinematográfico analógico. La cooperación iberoamericana en la era digital. Congreso Internacional de la Asociación Española de Investigadores de la Comunicación (AE-IC), Málaga.

RODRÍGUEZ, L. (2014): De «gira» por los festivales: Patrones migratorios del cine latinoamericano. Secuencias: revista de historia del cine, no. 39. Disponible en: https://revistas.uam.es/secuencias/article/view/5840 
RUD, L. (2011): Consumo. Un nuevo modo de ir al cine: Imax y Hoyts Dot. VI Jornadas de Jóvenes Investigadores, UBA.

SILVA, D. (2007): Vizinhos distantes. Circulação cinematográfica no Mercosul. São Paulo: Annablume.

SIMIS, A. (2015): Economia Política do Cinema: a exibição cinematográfica na Argentina, Brasil e México. Versión. Estudios de Comunicación y Política, no. 36, pp. 54-75.

SORIA, C. (2016): Cine (Trans) nacional: festivales de cine y marcas de identidade. Nuevo Mundo Mundos Nuevos [En ligne].

Disponible en: http://journals.openedition.org/nuevomundo/69765.

DOI: https://doi.org/10.4000/nuevomundo.69765

UNESCO (2017). 2018 Global Report “Reshaping Cultural Policies”. Paris: UNESCO. 


\section{Anexos}

Anexo 1. Total de coproducciones argentino-brasileñas (2005-2016)

\begin{tabular}{|c|c|c|c|c|c|c|c|c|}
\hline$\#$ & Ano & Título & Diretor & Gênero & País Coprodutor & Ren & $(\mathrm{R} \$)$ & Público \\
\hline 1 & 2016 & Paulina & Santiago Mitre & Ficção & Argentina & $\mathrm{R} \$$ & 209.171 & 15.324 \\
\hline 2 & 2016 & $\begin{array}{l}\text { Mate-me por } \\
\text { favor }\end{array}$ & $\begin{array}{l}\text { Anita Rocha da } \\
\text { Silveira }\end{array}$ & Ficção & Argentina & $\mathrm{R} \$$ & 115.883 & 9.825 \\
\hline 3 & 2016 & \begin{tabular}{|lr} 
Lua & em \\
Sagitário
\end{tabular} & Márcia Paraíso & Ficção & Argentina & $\mathrm{R} \$$ & 34.702 & 3.078 \\
\hline 4 & 2016 & O Ardor & Pablo Fendrik & Ficção & $\begin{array}{l}\text { Estados Unidos / } \\
\text { México / França / } \\
\text { Argentina }\end{array}$ & $\mathrm{R} \$$ & 3.710 & 234 \\
\hline 5 & 2015 & Divã a 2 & $\begin{array}{l}\text { Paulo } \\
\text { Fontenelle }\end{array}$ & Ficção & Argentina & $\mathrm{R} \$$ & .982 .583 & 164.589 \\
\hline 6 & 2014 & $\begin{array}{|ll|}\text { A Oeste } & \text { do } \\
\text { Fim } & \text { do } \\
\text { Mundo } & \\
\end{array}$ & $\begin{array}{l}\text { Paulo } \\
\text { Nascimento }\end{array}$ & Ficção & Argentina & $\mathrm{R} \$$ & 58.339 & 4.780 \\
\hline 7 & 2014 & $\begin{array}{|ll|}\begin{array}{l}\text { Coração } \\
\text { Leão }\end{array} & \text { de } \\
\end{array}$ & \begin{tabular}{|l} 
Marcos \\
Carnevale
\end{tabular} & Ficção & Argentina & $\mathrm{R} \$$ & 372.721 & 25.936 \\
\hline 8 & 2013 & $\begin{array}{|lr|}\text { A } & \text { Memória } \\
\text { que r r me } \\
\text { Contam }\end{array}$ & Lúcia Murat & Ficção & Chile / Argentina & $\mathrm{R} \$$ & 68.729 & 6.204 \\
\hline 9 & 2013 & \begin{tabular}{|l|} 
A Sorte em \\
suas Mãos
\end{tabular} & Daniel Burman & Ficção & Argentina & $\mathrm{R} \$$ & 316.109 & 25.088 \\
\hline 10 & 2013 & $\begin{array}{l}\text { Habi, } \quad \text { A } \\
\text { Estrangeira }\end{array}$ & \begin{tabular}{|l} 
Maria \\
Florencia \\
Alvarez
\end{tabular} & Ficção & Argentina & $\mathrm{R} \$$ & 73.133 & 5.681 \\
\hline 11 & 2013 & \begin{tabular}{|lrl} 
Juan & e & a \\
Bailarina &
\end{tabular} & $\begin{array}{l}\text { Raphael Gayer } \\
\text { Aguinaga }\end{array}$ & Ficção & Argentina & $\mathrm{R} \$$ & 50.125 & 4.256 \\
\hline 12 & 2012 & $\begin{array}{|ll|}\text { Histórias } & \\
\text { Que } & \text { Só } \\
\text { Existem } & \\
\end{array}$ & Julia Murat & Ficção & $\begin{array}{l}\text { Argentina } \\
\text { França }\end{array}$ & $\mathrm{R} \$$ & 81.756 & 8.824 \\
\hline
\end{tabular}




\begin{tabular}{|c|c|c|c|c|c|c|c|c|}
\hline & & $\begin{array}{l}\text { Quando } \\
\text { Lembradas }\end{array}$ & & & & & & \\
\hline 13 & 2012 & \begin{tabular}{|l|} 
Infância \\
Clandestina
\end{tabular} & Benjamin Ávila & Ficção & $\begin{array}{l}\text { Argentina } \\
\text { Espanha }\end{array}$ & $\mathrm{R} \$$ & 379.217 & 32.908 \\
\hline 14 & 2012 & \begin{tabular}{|l|} 
Violeta Foi \\
Para o Céu
\end{tabular} & Andrés Wood & Ficção & Chile / Argentina & $\mathrm{R} \$$ & 362.595 & 37.243 \\
\hline 15 & 2011 & \begin{tabular}{|l} 
Estamos \\
Juntos
\end{tabular} & Toni Venturi & Ficção & Argentina & $\mathrm{R} \$$ & 266.546 & 33.187 \\
\hline 16 & 2010 & $\begin{array}{l}400 \text { contra } 1 \\
\text { - a História } \\
\text { do Comando } \\
\text { Vermelho }\end{array}$ & Caco Souza & Ficção & Argentina & $\mathrm{R} \$$ & 1.078 .111 & 127.450 \\
\hline 17 & 2010 & Olhos Azuis & José Joffily & Ficção & Argentina & $\mathrm{R} \$$ & 133.822 & 15.499 \\
\hline 18 & 2009 & \begin{tabular}{|l} 
A Festa da \\
Menina \\
Morta
\end{tabular} & $\begin{array}{l}\text { Matheus } \\
\text { Nachtergaele }\end{array}$ & Ficção & $\begin{array}{l}\text { Portugal } \\
\text { Argentina }\end{array}$ & $\mathrm{R} \$$ & 131.091 & 16.414 \\
\hline 19 & 2008 & \begin{tabular}{|l|} 
Café dos \\
Maestros
\end{tabular} & Miguel Kohan & Documentário & Argentina & $\mathrm{R} \$$ & 282.668 & 33.150 \\
\hline 20 & 2007 & O Passado & $\begin{array}{l}\text { Hector } \\
\text { Babenco }\end{array}$ & Ficção & Argentina & $\mathrm{R} \$$ & 1.608 .326 & 174.809 \\
\hline 21 & 2005 & $\begin{array}{l}\text { Diário de um } \\
\text { Novo Mundo }\end{array}$ & $\begin{array}{l}\text { Paulo } \\
\text { Nascimento }\end{array}$ & Ficção & $\begin{array}{l}\text { Portugal } \\
\text { Argentina }\end{array}$ & $\mathrm{R} \$$ & 67.809 & 12.685 \\
\hline
\end{tabular}

Fuente: OCA-ANCINE 